\title{
How Contextual Factors Fuel Corruption in the Procurement Cycle of Construction Projects
}

\author{
Jones Kalyongwe ${ }^{1, *}$, Mubiana Macwan'gi ${ }^{1}, B$ alimu Mwiya ${ }^{1}$, Mundia Muya ${ }^{1}$, Jonathan Tambatamba ${ }^{1}$, \\ Lungowe Matakala ${ }^{1}$, Nalukui Milapo ${ }^{1}$, Khatibu Kazungu ${ }^{2}$, Vincent Byusa ${ }^{3}$ \\ ${ }^{1}$ University of Zambia, Zambia \\ ${ }^{2}$ Open University of Tanzania, Tanzania \\ ${ }^{3}$ The National University of Rwanda, Kigali, Rwanda
}

Copyright $(\mathrm{C} 2018$ by authors, all rights reserved. Authors agree that this article remains permanently open access under the terms of the Creative Commons Attribution License 4.0 International License

\begin{abstract}
Corruption has long pervaded the construction industry in Zambia, as it involves interaction between various stakeholders and involves a certain level of cooperation in order to coordinate the numerous activities which make up the construction process. The balance between activities which legally facilitate this process and those which are tainted by concepts of corruption is not always clear. Corruption is commonly defined as the "abuse of public power for private benefit" (Rodriguez et al., 2005, p. 383), but it goes beyond public officials and often affects businesses and supply chains as well (Dixit, 2015; Cuervo-Cazurra, 2016). Corruption has many connotations and interpretations, varying according to time and place (Rose-Ackerman and Palifka, 2016). The common dimensions of corruption involve exchange, violation of norms, abuse of power, indirect victims and secrecy (Rabl and Kühlmann, 2008). The scale and complexity of many construction projects, together with the number of parties participating, the geographical locations where they are performed and the legal systems to which they are exposed can make them especially prone to bribery and corruption. This paper therefore is focused on how contextual factors fuel corruption in procurement in the Construction Sector. Findings from a two years' study, Options for Reducing Corruption in Procurement: The Case of the Construction Sector in Zambia, reveal that how people are socialised to relate to parents, elders and leaders has an effect on how corruption is perceived. In addition, evolving culture has led to a misinterpretation of cultural norms and its current use is aiding corruption.
\end{abstract}

Keywords Culture, Corruption, Contextual Factors, Procurement, Construction Industry

\section{Introduction}

Corruption occurs in various forms at different stages of the procurement cycle in construction but is difficult to identify when it happens. There is no universally-accepted definition of corruption, although literature suggests corruption is misuse of an office for personal gain [1]. It involves behaviour in which the office holder improperly and unlawfully advance private interests over the interest of the office or position they occupy by misusing it for personal gain. However according to [2], having a single definition may not even be helpful since corrupt practices change from time to time, depending on social and political dynamics. In an effort to understand the nature of corruption, different approaches of identifying and estimating the extent of corruption exist.

Macwan'gi et al. [3] state that corruption has crippling effects on national socio-economic development and governance systems. Despite many anti-corruption measures being implemented over the years, most governance and corruption indicators show that corruption remains a major challenge in Zambia. The 2014 National Corruption Diagnostic Study [4] shows that corruption is the third most serious problem in Zambia (unemployment and high cost of living being first and second respectively). Similarly, the World Economic Forum's 2013-2014 Global Competitiveness Report identified corruption as the second most problematic factor (after access to financing) for doing business in Zambia; and the Global Economic Crime Survey-Zambia Report [5] indicate that bribery and corruption was the second most prevalent form of economic crime in Zambia.

Very little literature exists on corruption in procurement in the construction sector in Zambia. However, the literature that exists suggests that the construction sector is riddled with corruption. Transparency International [6] indicate that corruption is one of the main unethical practices in the construction sector, while Shakantu [7] observes that corruption in the construction industry is one "area which everybody in the industry knows about but nobody wants to go there". Similarly, Sichombo et al., [8] 
reveal that the construction sector in Zambia is perceived to be the most corrupt by $35 \%$ of the respondents (followed by the consultancy sector at 33\%). Additionally, Mukumbwa and Muya [9] report that the prevalence of unethical practices was in all phases of the procurement cycle of construction projects in Zambia.

Because corrupt acts are often masked, conducted in secrecy and not exposed in public [10] it is important to understand what drives corruption in procurement of construction projects in Zambia. This paper focuses on contextual factors as contributors of corruption. Contextual factors are said to be factors that reflect a particular context, characteristics unique to a particular group, community, society and individual. Contextual environmental and personal factors play an essential part in how corruption manifests and how it affects procurement of construction projects in Zambia. Understanding these factors in the Zambian context would enable evidence based anti-corruption solutions. The fact that parties involved in the corruption are in most cases satisfied with the perceived gain from their acts makes awareness of contextual factors critical.

Considering the socio-cultural environmental factors such as cultural norms gives an indication of how and why corruption takes place. Norms are the agreed upon expectations and rules by which a culture guides the behaviour of its members in any given situation. Members of a culture must conform to its norms for the culture to exist and function. They first must internalise the social norms and values that dictate what is "normal" for the culture; then they must socialise, or teach norms and values to, their children. If internalisation and socialisation fail to produce conformity, some form of "social control" is eventually needed. Social control may take the form of ostracism, fines, punishments, and even imprisonment. Yang [11] asserts that, activities in certain cultural circles, which might be regarded as essential to getting the job done, and a lawful means of doing so, may well be seen elsewhere as dishonest, or unlawful. For instance, in China, gift-giving is not only seen as obligatory in certain contexts, but also as a legitimate solution when, for instance, trying to obtain and change job assignments, buy certain foods and consumer items, and obtain better education. Yang [12] writes, "In the Chinese cultural discourse there is often a fine line between the art of guanxi and bribery". For instance, bribery and corruption are pejorative, negative terms, whereas guanxi connotes "human sentiments" friendship, long-term personal relationships, and an image of people helping one another. So there is a good side of guanxi which bribery does not have. It follows that if the two parties do not have a prior personal relationship already, such as shared native homes, kin relationship, and one party is seen to help the other, then society will surmise that there is bribery going on".

In Tanzania, one of the cultures that encourage corruption is that of "Achievers". This entails the treating or regarding of openly corrupt individual in society as achievers.

In Zambia, the cultural setup is influenced by how people are socialised to relate to parents, elders and traditional leaders in a community setting and employers, superiors and leaders in a formal work environment. For example, the young cannot question parents and elders. Likewise, at places of work juniors or subordinates cannot question their superiors or employers. This has resulted in leaders or those with authority acting with impunity. Historically, in colonial times subjects' submissiveness was equated to "loyalty to authority". Today this is visible in some management styles of institutions, where submission still shows loyalty to authority. The study views contextual factors from an organisational and individual perspective. Therefore the objectives of the study were to identify:

i. organisational contextual factors that facilitate corruption in procurement of construction projects; and limit adherence to anti-corruption and procurement laws in construction; and

ii. social economic contextual factors that facilitate individuals to engage in corrupt practices in procurement of construction projects; and limit adherence to anti-corruption and procurement laws in construction. This information is based on research findings of the two years study on corruption in procurement in the construction sector in Zambia and a comparative study in Rwanda and Tanzania

\section{Methods}

The methodology used both qualitative and quantitative research methods; and data was collected using three different tools: a focus group discussion guide; an in-depth interview (IDI) guide; and a survey questionnaire (SQ). This methodology allowed for triangulation.

The method used took the descriptive and diagnostic category which entailed the formulation of the objectives of the study, design of the method for data collection, selecting sample size, collecting data, processing and analysing data and reporting the findings [13]. This design allowed examination of relationship between variables though no causal inference could be established because data was collected simultaneously and the researchers could not manipulate any variables by merely interpreting [14].

The stakeholders who participated in the study included members of the community, private institutions, government, statutory bodies, academic institutions, regulatory and enforcement agencies, civil society and cooperating partners. From the sample target of 893 respondents, 737 people took part in the survey; 120 participants took part in the FGD; and there were 135 
interviewees who participated in the IDIs. The study participants and respondents were drawn from 10 different districts around Zambia. Tanzania and Rwanda were used for comparison purposes. This paper is based on the results of the study on 'Options for Reducing Corruption in Procurement: The Case of the Construction Sector in Zambia'. The study was conducted in 12 districts drawn from five provinces of Zambia in December 2015.

The overall objective of the study was to examine the extent and nature of corruption in the procurement of construction projects in Zambia. One specific objective was to identify contextual factors that facilitate corruption in procurement in the construction sector. The study used a cross sectional case study design. To allow for an in-depth investigation and understanding of complex and multiple factors associated with corruption in the procurement cycle of the construction sector, both qualitative and quantitative multiple but complementary research methods were used. The research protocol was approved by the Research Ethics Committee in Zambia. Specific methods were in depth interviews (IDI) with 137 informants, 12 focus group discussions (FGD) with community members within the vicinity of selected construction projects, stakeholders' survey covering a purposefully selected sample of 737 and review of project records. The study was conducted over a period of 2 years and generated a wealth of data from which several scholarly papers can be obtained and disseminated.

\section{Results}

According to the study in Zambia, Tanzania and Rwanda conducted in 2016, findings revealed that how people are socialised to relate to parents, elders and traditional leaders has an effect on how corruption is perceived. In addition, evolving culture has led to a misinterpretation of cultural norms and its current use is aiding corruption. Other findings show that there were inadequate monitoring systems within the organisations and that there was unethical behaviour, lack of morals, a desire to amass wealth, and poverty facilitated corruption in procurement of construction projects.

The study showed that the contextual factors that lead to corruption ranged from cultural setups, organisational and personal factors, to the way people perceive corruption. In Rwanda some of the contextual factors found during the study were; low salaries, lack of strong punishment for people involved in corruption, weak laws and the lack of seriousness when enforcing the laws. At each procurement stage, it was established that, at design stage, low salaries were top ranked while at tendering and evaluation stages greed and lack of integrity were prominent. At contract management, negotiation and implementation stage greed and lack of integrity were cited as most prevalent. As for socio-economic factors that cause corruption, high propensity for wealth was cited at all the stages in the procurement cycle.

In Tanzania, the study found out that, selfishness or greed was the key driver of corruption in most stages of the procurement process. Ease with which clients and providers could cheat was a key reason as to why there was corruption at the contract implementation stage, while, collusion was also found between the procuring entity staff and its clients at tendering and evaluation stage.

In Rwanda, the study also found that contextual factors that influenced corrupt practices were low salaries, lack of strong punishment for people involved, weak laws and lack of seriousness when enforcing the laws. They also said, poverty, weak values, sheer greed, poor services and high quest for wealth contributed to the scourge.

In Zambia, the study found out that there were various reasons that influenced engagement in corrupt practices among Clients, Consultants and the Contractors with the most common reason across the three being greed. The study further showed that other factors like loopholes in the system caused by lack of monitoring and supervision and also the lack of serious measures taken against people that engage in corrupt activities were a contributing factor among contractors and clients. Amongst the three categories, the study showed that corruption drivers for Clients were: greed, poverty, loopholes in the procurement processes, and lack of serious measures taken against culprits engaged in corrupt practices and desperation to get wealthy. As for Contractors, wanting to get the job at all costs and stiff competition, coupled with greed and weak systems (supervision and monitoring) and lack of tough punishment for offenders fueled corruption. While for Consultants, greed, insufficient work in the construction sector and lack of integrity were cited as prominent. It is evident from above literature and findings that, contextual factors have a major bearing on corruption in the construction sector.

The hypothesis that the study aimed to prove or disprove was:

$H_{0}$ : Corruption in the construction sector is fuelled by contextual factors such as political interference

Findings revealed that corruption in the construction sector is fuelled by Contextual factors such as political interference. However, of particular interest are weak laws and failure to enforce disciplinary measures are identified as one of the factors not fuelling corruption in the construction sector.

On factors that make it easier for organisations to engage in corrupt practices in the construction sector, respondents were shown a list of organisational factors and asked to select the top five factors that made it easier for organisations to engage in corrupt practices in the construction sector. The respondents' resulting top five factors were as follows: 417 respondents (57\%) picked 'Poor accountability' as their first; 412 respondents picked 
'Political interference' as their second; 279 respondents (38\%) picked 'Failure to blacklist offenders' as the third; then 275 respondents (37\%) picked 'Bad governance' as the fourth; and 260 respondents $(35 \%)$ each picked 'Limited prosecution' and Weak regulations' as the fifth.

Similarly, respondents were shown a list of Socio-economic factors and requested to select the top five factors that facilitate and limit adherence to anti-corruption and procurement laws and regulations in construction. The resulting top five socio-economic factors were as follows: 620 respondents (84\%) picked 'Greed' as their first factor; 561 respondents (76\%) picked 'Poverty' as their second; 531 respondents (72\%) picked 'High quest for wealth' as the third; then 523 respondents (71) picked 'low salaries' as the fourth; and 462 respondents $(63 \%)$ picked 'weak morals or values' as the fifth.

Some aspects of the Zambian culture that encourage corruption include:

- "People who are known to have acquired wealth through corruption are looked at as idols";

- "General perception that people reap from what they do and being gratified for services even when they are paid for it";

- "Poor work attitude, lack of commitment; and public being passive"; and

- "Poverty and lack of information about corruption".

The following cultural norms or sayings have been misinterpreted to fuel corruption:

a) Ubomba mwibala: is a saying from the Northern Province of Zambia which says "You reap where you saw". But it has been misinterpreted to mean, a person who is in-charge of a project should benefit from it, by using their position to amass wealth illegally;

b) Kwasha mukwenu: is a saying from the North-western Province of Zambia which says "be a brother's keeper". But it has been misinterpreted to mean, people you know should be favoured over and above others regardless of whether they deserve to win a tender or not;

c) Wako ni wako: is like Kwasha mukwenu, but principally meaning one should help their kin and kith regardless of whether they deserve to win a tender, thus breeding nepotism in contract awards; and

d) Nichekeleko: means, what is in it for me or scratch my back I will also scratch yours. This breeds "palm oiling" of officials responsible for managing the procurement processes.

\section{Discussion}

Reasons for undertaking the study by the Authors:

\section{Rationale of the Study}

The construction sector in Zambia is riddled with bribery, extortion, bid-rigging, collusion and many other forms of corruption (Mukumbwa: 2014). According to the 2014 TI Corruption, Perception Indices, Zambia is the 15th least corrupt country in Sub Saharan Africa (SSA). Additionally, the Auditor General's Reports has over the years, been citing numerous examples of corruption in procurement in Zambia. Findings indicate that corruption was very prevalent in the construction sector in Zambia. Sixty-three $(63 \%)$ of respondents indicated that corrupt practices were 'extremely common' in procurement in the construction sector, $26 \%$ stated that it was 'fairly common'. A Pearson Chi-square test, (with a p-value of .002) confirms that corrupt practices in procurement in the construction sector in Zambia are 'fairly common' to 'extremely common'. Similarly, findings show that corruption in procurement in the construction sector is 'a very serious problem' to 'serious problem' (with Chi-Square p-value of .001). Additionally, the Tendering/sourcing phase was found to be the phase at which corruption is most common (as identified by $30 \%$ of respondents) followed by Contract Negotiation \&award (21\%), and Tender evaluation \&supplier selection (19 while the Requirement definition/ specification phase is the phase at which corruption is least common (4\%). Thus, in terms of coming up with measures that address corruption at the various phases of procurement in the construction sector in Zambia, more attention should be paid to the phases that are more at risk.

An important line of thinking in the corruption literature argues that the economic benefits of corruption outweigh the costs [15-17]. Rooted in Merton's [18] discussion of the latent functions of the political machinery, this functional theory of corruption argues that the buying and selling of political favours have (certain) political and economic advantages.

One point often made is that bribery "greases the wheels" by cutting red tape, and thus improving efficiency. According to Huntington [19], in terms of economic growth, the only thing worse than a society with a rigid, over-centralised dishonest bureaucracy, is one with a rigid, over-centralised, honest bureaucracy. On the political side, it is argued that corrupt practices are a means of integrating people in the political system.

The claim that corruption is politically integrative is, however, questioned by Johnson [20] who argues that corruption also has disintegrative features. According to Theobald as quoted by Iqbal et al., [21] provides a good overview of the functional and dysfunctional aspects of corruption in developing countries.

The arguments that corruption improves efficiency are based on the assumption that the economic costs of extensive public regulations may be reduced or avoided through bribery. Using data from three worldwide firm-level surveys, Kaufmann and Wei [22] examined the relationship between bribe payment, management time 
wasted with bureaucrats, and cost of capital. Contrary to the efficient 'grease' theory, they find that firms that pay more bribes are also likely to spend more, not less, management time with bureaucrats negotiating regulations, and face higher, not lower, cost of capital.

The Corruption Perception Index (CPI) 2015 released by Transparency International ranks Rwanda as the fourth least corrupt country in Africa and 44th globally. The report shows an improvement in Rwanda's percentage score from 49 up to 54 per cent [23]. Key to Rwanda's success in tackling corruption is a political will at high level of the State to address the issue of corruption and the political commitment in promoting good governance.

The country is enjoying the respect and support from foreign investors because it has created a business environment with more opportunities and less corruption. Key to Rwanda's success in fighting corruption is the political will that addresses the issue from those at the very top of the government. The literature suggests that political will is the most important element of an effective anti-corruption strategy. Without political will at the highest level of the government, it is almost impossible to combat corruption effectively. Apart from political will and strong leadership, the government has to set up a dedicated and independent anti-corruption institution i.e. the Office of Ombudsman in Rwanda, enact the right laws and policies to fight against corruption. Reflecting Rwanda's President Kagame's views on zero tolerance approach to corruption, the government put in place specific measures (Criminalising corruption) and made public pledges aimed at tackling corruption [24].

Thus, key ingredients driving Rwanda's success in curbing corruption when so many other countries have failed to do so is the effective implementation of anti-corruption policy. The policy is courageously implemented. To do so, leadership and political will matters; the anti-corruption agency has to be independent and credible with adequate resources. Citizens' mobilisation and support is central in fighting corruption. Furthermore, reforms have to be introduced to minimise the gains that can be obtained from corrupt practices, and increase detection rates and the size of the penalties. Not only tough talk but also through measures. Zambia and Tanzania can learn best practices as espoused in Rwanda, so as to reduce the incidence of corruption in the two countries as the case has been in Rwanda [25]. There are no known research results that have been obtained in Zambia on how contextual factors fuel corruption in other sectors of the economy

\section{Evidence Based}

Findings indicate that corruption was very prevalent in the construction sector in Zambia. Sixty-three $(63 \%)$ of respondents indicated that corrupt practices were 'extremely common' in procurement in the construction sector, $26 \%$ stated that it was 'fairly common'. A Pearson
Chi-square test, (with a p-value of .002) confirms that corrupt practices in procurement in the construction sector in Zambia are 'fairly common' to 'extremely common'. Similarly, findings show that corruption in procurement in the construction sector is 'a very serious problem' to 'serious problem' (with Chi-Square p-value of .001). Additionally, the Tendering/sourcing phase was found to be the phase at which corruption is most common (as identified by $30 \%$ of respondents) followed by Contract Negotiation \&award (21\%), and Tender evaluation \&supplier selection (19 while the Requirement definition/ specification phase is the phase at which corruption is least common (4\%). Thus, in terms of coming up with measures that address corruption at the various phases of procurement in the construction sector in Zambia, more attention should be paid to the phases that are more at risk.

\section{Conclusions}

The scale and complexity of many construction projects, the number of parties involved the geographical locations where they are performed and the legal systems to which they are exposed can make construction projects especially prone to bribery and corruption. The balance between activities which legally facilitate this process and those which are tainted by concepts of bribery, or corruption is not always clear. However, it was established that political interference was a major contextual factor that fueled corruption in procurement in the construction sector. In addition, how people are socialised to relate to parents, elders and leaders had an effect on how corruption was perceived. Evolving culture can be said to be responsible for the misinterpretation of cultural norms and its current use is aiding corruption.

\section{Acknowledgements}

The authors wish to acknowledge the British Academy and Department for International Development (BADFID) for commissioning and funding the two-year research project, part of whose findings were analysed in this paper.

\section{REFERENCES}

[1] Jill Wells "Corruption and collusion in construction: a view from the industry," in Søreide, T. and A. Williams (Eds.) Corruption, grabbing and development: Real world challenge, Edward Elgar Publishing, 2014.

[2] Vitoria, A., Kroeze, R. How history can help us think about corruption and anti-corruption. History \& Policy. Retrieved from http://www.historyandpolicy.org/opinion-articles/articles/h 
ow-history-can-help-us-think-about-corruption-and-anticorr uption Google Scholar. 2015

[3] Macwan'gi M., Muya M., Matakala L. and Milapo N., Evolving Cultural Norms at Crossroads with Legal Frameworks in Reducing Corruption in the Procurement of Construction Projects in Zambia, International Journal of Advances in Mechanical and Civil Engineering, ISSN: 2394-2827 Volume-4, Issue-5, http://iraj.in, 2017.

[4] Government of the Republic of Zambia, the 2014 National Corruption Diagnostic Study Government Printers, Lusaka 2014.

[5] PwC 2014. PwC. SMEs' access to public procurement markets and aggregation of demand in the EU. Study commissioned by the European commission, DG Internal Market and Services.

http://ec.europa.eu/internal_market/publicprocurement/docs /modernising rules/smes-access-and-aggregation-of-deman d_en.pdf., 2014 .

[6] Transparency International, Global Corruption Report: Corruption in Construction and Post-conflict Reconstruction. London: Pluto Press, 2005.

[7] Shakantu, W., Corruption in the construction industry, forms, susceptibility and possible solutions. Cape Town: University of Cape Town, 2006.

[8] Sichombo B., Muya M., Shakantu W. and Kaliba C., The Need for Technical Auditing in the Zambian Construction Industry, International Journal of Project Management. Vol. 27 (8), pp. 821-832. Available online: http://doi.10.1016/j.ijproman.2009.02.001, Elsevier, UK, 2009.

[9] B. Mukumbwa and M. Muya, Ethics in the Construction Industry in Zambia. International Journal of Construction Management. Vol. 13, (2), 2012.

[10] UKEssays, The Defining Of Corruption In Governments Politics Essay. [online]. Available from: https://www.ukessays.com/essays/politics/the-defining-of-c orruption-in-governments-politics-essay.php?vref=1 [Accessed 30 October 2017] 2013.

[11] Yang, Mayfair Mei-Hui (1989): “The gift economy and state power in China", Society for Comparative Study of Society and History, vol. 31, no. 1, 1989.

[12] Yang, Mayfair Mei-Hui, Gifts, Favours and Banquets: The Art of Social Relationships in China. Ithaca/London: Cornell University Press, 1994.

[13] Kothari, C. R. and Garg G., Research methodology Methods and Techniques - New Age International (P) Ltd. - New Delhi, 2014.

[14] Saunders, M., Lewis, P., and Thornhill, A., Research Methods for Business Students, 6th edition, Prentice Hall
2007.

[15] Nye, J. S., Corruption and Political Development: A Cost-Benefit Analysis', American Political Science Review, 61 (2). 417-427, 1967.

[16] Leff, Nathaniel H., "Economic development through bureaucratic corruption", American Behavioural Scientist, $8 / 3$ (November), pp. 8-14. (Re-published as chapter 24 in Political corruption. A Handbook. Heidenheimer et al, New Brunswick, 1989, Transaction Publishers, 1964.

[17] Huntington, S.P. (): "Modernisation and corruption", in Political order in Changing Societies, Samuel P. Huntington, and New Haven, Connecticut: Yale University Press. Pp. 59-71. (Republished in Political Corruption. A Handbook. Heidenheimer et al., New Brunswick, 1989, Transaction Publishers. Chapter 23, 1968.

[18] Merton, R.K., Social Theory and Social Structure. New York: Free Press, 1968.

[19] Huntington, S.P., "Modernisation and corruption", in Political order in Changing Societies, Samuel P. Huntington, and New Haven, Connecticut: Yale University Press. Pp. 59-71. (Republished in Political Corruption. A Handbook. Heidenheimer et al., New Brunswick, 1989, Transaction Publishers. Chapter 23, 1968.

[20] Johnson, S., D. Kaufmann and P. Zoido-Lobaton: "Regulatory discretion and the unofficial economy", American Economic Review Papers and Proceedings, vol. 88 , no. 2,1998 .

[21] Zahid Iqbal, Hassan Ahmad, Muhammad Ahmad Mushtaq, Shahid Iqba, Causes of Corruption in Public Sector Organization: The Study of District Bahawalnagar, Punjab, Management and Administrative Sciences Review e-ISSN: 2308-1368, p-ISSN: 2310-872X Volume: 4, Issue: 3, Pages: 837-845, 2015.

[22] Daniel Kaufmann, Shang-JinWei. NBER Working Paper No. 7093 NBER Program(s): International Trade and Investment. Does "Grease Money" Speed Up the Wheels of Commerce? 1999.

[23] Transparency International (2015) Corruption Perceptions Index 2015

[24] Muya M., Macwan'gi M., Mwiya B., Kalyongwe J., Tambatamba J., Matakala L., Kazungu K., Byusa V., Milapo N., Options for Reducing Corruption in Procurement: The Case of the Construction Sector in Zambia, Final Project Report, Lusaka, Zambia, 2018.

[25] Muya M., Macwan'gi M., Mwiya B., Kalyongwe J., Tambatamba J., Matakala L., Kazungu K., Byusa V., Milapo N., Options for Reducing Corruption in Procurement: The Case of the Construction Sector in Zambia, Final Project Report, Lusaka, Zambia, 2018. 